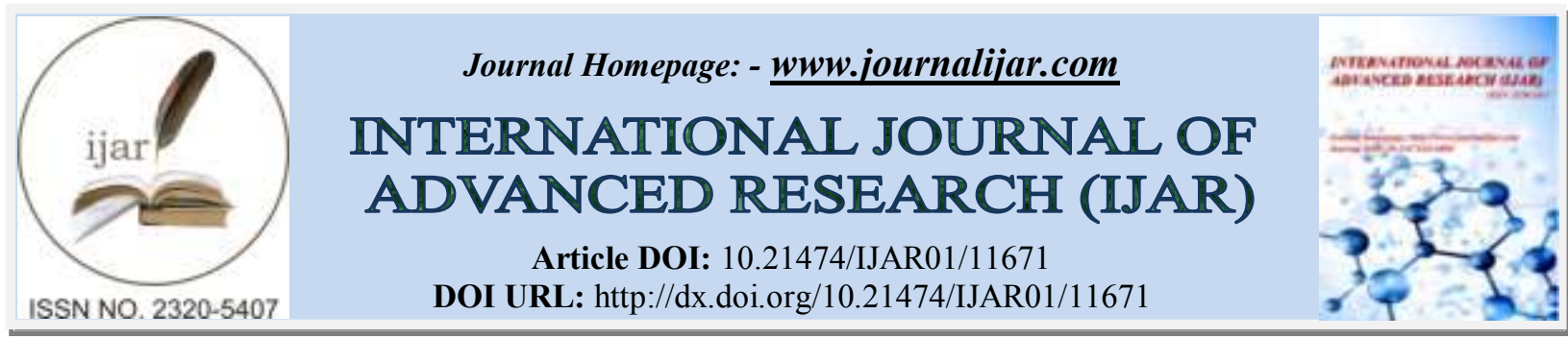

RESEARCH ARTICLE

\title{
CONCEPTUAL FRAMEWORK OF INVETORY MANAGEMENT: A USEFUL GUIDE TOWARDS THE MAJOR ASPECTS OF THE SUBJECT
}

\author{
Numaira Showkat ${ }^{1}$ and Dr. Khurshid $\mathrm{Ali}^{2}$ \\ 1. Research Scholar,Department of Management Studies, University of Kashmir. \\ 2. Assistant Professor, Business Division, Higher College of Technology, United Arab Emirates.
}

\section{Manuscript Info}

..........................

Manuscript History

Received: 10 July 2020

Final Accepted: 14 August 2020

Published: September 2020

Key words:-

Inventory Management, Lead Times, Carrying Costs, Inventory Forecasting, Inventory Valuation

\section{Abstract}

The term 'inventory' refers to the stockpile of the products that a firm is offering for sale and the components that make up the products. Thus, inventory includes the stock of raw materials, goods-in-process, finished goods and stores and spares. Inventories have assumed colossal proportions in manufacturing organizations and a substantial amount of working capital is tied up in inventories. Industrialized countries have largely overcome the uncertainties by bringing in force regulating mechanism and have minimized transportation delays etc. and have substantially reduced the time lags and have reduced inventories as a result. There are countries to cite where organizations operate on zero inventory levels as they are certain about items that they have ordered will reach to the factory premises on time and date they were supposed to. However, it will still take time to have such mechanism in Indian settings and probably we are bound to have inventories till we ward off uncertainties as they did in advanced countries. The aim of the paper is to provide sufficient knowledge on the subject matter which will be helpful in understanding the subject well.An attempt has been made to summarize and present the theories, techniques and important concepts of inventory management.

Copy Right, IJAR, 2020,. All rights reserved.

\section{Introduction:-}

Meaning and Definition of Inventory

Inventory is composed of assets that will be sold in future in the normal course of the business operations. It is a stock of goods that is maintained to facilitate the continuous production of goods and services. The term 'inventory' refers to the stockpile of the product a firm is offering for sale and the components that make up the products. As per accounting terminology, inventory means "the aggregate of these items of tangible property which (I) are held for sale in the ordinary course of business, (II) are in process of production for sale, and (III) are to be currently consumed in the production of goods or services to be available for sale." Thus inventory includes the stock of raw materials, goods-in-process, finished goods and stores and spares.

Inventory is often where the biggest costs are hidden in businesses (Harrington, 1996).In fact, inventory control has been studied for several decades for cost savings of enterprises (Axsater, 2000, Moinzadeh, 2002, Zipkin, 2000). This is the reason why inventory management is the subject of great importance. Inventory management may be defined as the sum total of those activities, which are necessary for the acquisition, storage, sale and disposal of 
source of material. Inventory management is concerned with the determination of the optimal level of investment for each component of inventory and the inventory as a whole relates to the efficient use of the components and the operation of an effective control and review mechanism. The management of inventory requires careful planning so that both the excess and the scarcity of inventory in relation to the operational requirement of an undertaking may be avoided. Therefore, it is essential to have a sufficient level of investment in inventories. The following activities fall within the range of inventory management: control of lead times, carrying costs of inventory, inventory forecasting, inventory valuation, inventory visibility, future inventory price forecasting, physical inventory, available physical space for inventory, quality management, replenishment, returns and defective goods and demand forecasting.

\section{Nature of Inventories}

The stock of the product that a company is manufacturing for sale makes inventories. The different forms of inventories are: Raw Materials, Work-in- Process/Semi-Finished Goods, Finished Goods and Stores and Spares.

1. Raw material Inventory comprises of the basic inputs that are converted into finished products through manufacturing process. These are purchased and stored for future productions. Stock of Raw Material facilitates production. e.g., cotton is raw Material for the production of yarn.

2. Work-in-Process/Semi-Finished Goods inventories are those semi-finished products which need more work before they become finished products for sale. The process like finishing, packaging, rubbing, colouring, testing or any other such process which is required before sending the product for sale.

3. Finished Goods are completely finished products which are ready for sale. Stock of finished goods is important for smooth marketing operation.

4. Stores and Spares are small part of the total Inventory which do not enter the production directly but are very necessary for production process. They are very critical. Their absence may hamper the whole production run, which can result in huge losses. They do not involve significant investment. Their stock includes oil, grease, lubricants, nuts, bolts, and machine parts which are more vulnerable to wear and tear. In addition to Stores and Spares firms also maintain supplies which include office and plant cleaning materials like light bulbs, brooms, soap, insecticides and anti-rodent chemical sprays etc.

\section{Functions of Inventory}

It is an established opinion that all the three components of inventory work as blood vessels in the operational functioning of an organization. The more efficiently the inventories are held, the more flexible the organizational run is ensured. The main functions of inventories are:

\section{Maintain a Rate of Flow through a Process}

Every inventory type works as a link among the operational processes. It narrows the gap between long awaiting customers and manufacturer; between manufacturer and supplier; and more importantly, between the machine in one section and the one in another section. The efficient management of finished goods relieves the customer from unnecessary waiting; the properly handled raw material inventory reduced the gestation period of manufacturing of a product, and similarly the maintained in-process inventory renders the machines to operate simultaneously.

\section{Covering gaps in a discontinuous Process}

The major function of inventory is to cover the gaps in any discontinuous process. Time lag between supply of raw material and the receipt of the same, gestation period between the processing of the materials and finished products; and in time interaction between the product and the customer. An efficient inventory management system minimizes such complicacies with ease.

\section{Providing Multiple Sources of Supply}

The vital function of an efficient inventory system is to provide various sources of supply both of raw materials to the manufacturer and goods to the customer.

\footnotetext{
Allowing Purchases in more economic lots

The more commonly studied inventory decisions are those which involve production or procurement of material in lots and those which allow the firm to respond to most fluctuations in supply, process, or demand. Thus the function of inventory management should be to procure raw materials in most economical ways.
} 


\begin{abstract}
Allowing Temporary variations in operating Rates
The operating patterns of companies differ from each other by more than one dimension. Some companies resort to three shifts operating, while as some operate on one shift rate. And within a company, there are urges of independence between supplier and user. Even though assembly might be a continuous process, it might prove more economical, at times, to operate on partly manufacturing by making larger, more infrequent lots.
\end{abstract}

\title{
Meeting Fluctuations in Supply or Demand or Storing Perishables
}

Many companies operate in environments with major seasonal fluctuations. They do not necessarily operate at a rate which fluctuates immediately with the demand or supply levels. Their supplies such as labour or raw material may be available only at a different rate. An inventory system is used to balance the two rates. An efficient inventory system is such which controls properly over the storing of perishables.

\section{Inventories as Motivators}

The presence of inventory has a motivational effect on the people around it. It is common belief that large piles of goods displayed in a super market will lead the customer to buy more. In contrast, too much piled up in everyone's way leaves a negative impression on buyer and employee alike. It is understood that workers should be able to see the work ahead of them in an appropriate amount. If there is not enough work in sight, they may slow down to protect themselves short hours or layoffs.

\section{Motives for holding Inventories}

The holding up of inventories involves tying up of the concern's funds and carrying costs. If it is expensive to hold inventories, why do concerns hold inventories? There are three motives for holding inventories:
a) Transaction motive;
b) Precautionary motive; and
c) Speculative motives.

When inventories are held merely for the purpose of carrying on transactions smoothly, and at the same time, ensuring that the cost of ordering is kept minimal, such a motive is called transaction motive. However if inventories are increased as a hedge or protection against stock-out when it becomes clear to the management that the lead-time for any particular item is likely to increase or there is a possibility of short supply. This increasing of the safety stock arises from purely a precautionary motive. And lastly, a situation may arise when an all- round price increase is expected due to market demand or due to changes in cost, in such a situation, the company management is keen to hold on to the inventories or increase them in order to get a better price for the finished goods. Such a motive is known as the speculative motive.

\section{The Objective of Inventory Management}

To optimize the size of inventory in a firm so that smooth performance of production and sales function may be possible at minimum cost. The objective of a good inventory management is to place an order at the right time, from the right source, to acquire the right quantity, at the right place. The success of inventory management depends upon two fundamental principles (i) how much to re-order (order quantity) and (ii) when to re-order (order level). The following objectives should be kept in mind while developing an appropriate level of inventory:

1. As investment in inventories involves costs, it should be kept minimum so that undue amount is not locked up.

2. A firm should make effective efforts in buying quantity of raw materials in accordance to its needs.

3. Continuous efforts should be made by the firm to shorten the production cycle. The long production cycle runs heavy costs and thus gives rise to the risk of the extra investment.

4. Inventory in a firm should be kept to such a level that smooth and unhampered production is ensured without any obstruction.

5. A firm should maintain sufficient amount of finished goods to meet the demand of customers regularly because if it is not done then the customers may shift to the competitors, which will amount to a permanent loss to the firm.

6. To the extent possible, a firm should try to minimize the possibility of the risk of loss through obsolescence or shrinkage in the market value between the time of purchase of manufacture on the one hand and the time of sale, on the other.

7. To serve as a means for the location and disposition of inactive and obsolete items of store.

8. To keep all the expenditures within the budget authorization. 
Therefore Inventory management should strike a balance between too much inventory and too less inventory. The efficient management and effective control of inventories help in achieving better operational results and reducing investment in working capital. It has a significant influence on the profitability of a concern. Various types of businesses control inventory for the following purposes:

9. A firm should work meticulously to minimize the carrying cost and time.

10. A firm should strive to minimize costs and maximize profits

11. A firm should make sufficient provisions against strikes and work stoppages and acts of God.

\title{
Inventory Control
}

The term inventory control has been defined by American Production and Inventory Control Society as "the technique of maintaining the stock keeping items at desired level whether they are raw materials or work-in-progress or finished goods."(APICS, 1996) Inventory control refers to a system, which ensures the supply of required quantity and quality of inventory at the required time and at the same time prevents unnecessary investment in inventories. Designing a sound inventory control system is, in a large measure, a balancing operation. Inventory control is concerned with keeping the desired inventory level and maintaining it at the minimum inventory carrying cost.

The efficiency of inventory control affects the flexibility of the firm. Inefficient procedures may result in an unbalanced inventory, sometimes out of stock or overstocked, necessitating excessive investment. These inefficiencies ultimately will have an adverse effect on profits. Turning the situation around, differences in the efficiency of the inventory control for a given level of flexibility affect the level of investment required in inventories. The less efficient the inventory control, the greater is the investment required. Excessive investment in inventories increases costs and reduces profits. Thus, the effects of inventory control on flexibility and on the level of investment required in inventories represent two sides of the same coin. In managing inventories, the firm's objective should be in consonance with the wealth maximization principle.

\section{Various Techniques of Inventory Control}

In order to determine the optimum level of inventory, the following inventory management tools and techniques should be considered:

\begin{abstract}
ABC Analysis
$\mathrm{ABC}$ (always better control) or CIE (control by importance and exception) underlines a very important principle 'vital few- trivial many' (Chunawalla, Patel 1994). It is an analytical approach aimed at keeping the investment low and also avoiding the stock out of critical items at the same time. A stock out of production parts and materials can be costly, production may be held up if either item is out of stock. Safety stocks almost always are a better value for low cost items they are far expensive ones. Modern inventory control system takes this into account by classifying items by value of usage. The high value items have lower safety stocks, because the cost of protection is so high. However, the low-value items carry much higher safety stocks. This necessitates the controlling manager to recognize the rupee importance of each individual inventory items. Each item should be studied in terms of its price, usage and lead time as well as specific procurement or technical problems. On this basis, it would be easier to allocate departmental effort and expense to tasks of controlling thousands of inventory items.
\end{abstract}

$\mathrm{ABC}$ analysis is a basic analytical management tool which enables top management to place the efforts where the results will be greatest. This technique, popularly known as 'Always Better Control or the Alphabetical Approach' provides maximum overall protection against stock outs for a given investment in safety stocks. This analysis reveals a measure of the inventory importance of each component helping to put 'first things first'. It is an analytical approach that provides "the most control for the least amount of controlling.

Herbert J. Richmond designates this plan as Proportionate Value Analysis (PVA). The procedure for ABC analysis consists of the following steps:-

a) Prepare a list of all items to be held in inventory

b) Average the items in order to value to be spent in descending order

c) Assign serial numbers to items as arranged above

d) Compute for each items percentage proper in the total for: (a) total cost -total cost of each item divided by total cost of all material, (b) items - number of items divided by total number of items

e) Convert simple percentage into cumulative percentage both for the items and value consumption 
A category items: The items covering up to certain percentage may be 65 percent of total consumption in value may be considered to be ' $A$ ' items

B category items: The next set of items whose aggregate value covers say 20 percent of the total may be considered as ' $\mathrm{B}$ ' items and

$\mathrm{C}$ category items: The remaining set of items whose aggregate value covers by 15 percent of the total may be put under ' $\mathrm{C}$ ' items. Finally find also the percentage of A, B and C group items in relation to total items.

The Table Exhibits the comparative importance of $A, B$ and $C$ group items:-

\begin{tabular}{|l|l|l|}
\hline \multicolumn{1}{|c|}{ Comparative Importance of A, B and C group items } \\
\hline \multicolumn{1}{|c|}{ Close control } & \multicolumn{1}{c|}{ B } & \multicolumn{1}{c|}{ Coderate control } \\
\hline $\begin{array}{l}\text { Budgeted almost on hand to mouth } \\
\text { approach }\end{array}$ & Based on past usage & When supply gets low, order more \\
\hline Close check on schedule revision & Some check on change in needs & No check against needs \\
\hline Continual expediting & Expediting for prospective shortage & No expediting \\
\hline Low safety stocks & Larger safety stocks & Large safety stocks \\
\hline Keep record of receipt and use & Keep record of receipt and use & No record and less paper work \\
\hline
\end{tabular}

After throwing light on $\mathrm{ABC}$ analysis and its uses, however, there are various other techniques which have come forth from time to time in order to arrive at a better control in inventory management. They are discussed in the following section.

\section{The HML Classification}

This method is similar to ABC classification. But in this case instead of the consumption value of items, the unit value of the item is considered. As the name itself implies, the materials are classified according to their unit value as high, medium or low valued items. The cut off points will depend on the individual items. For example, kerosene will be a low value item for a jeweler and a high value item for a shopkeeper. However, the focus in this classification is so directed as is control the purchase prices.

\section{The XYZ Classification}

The XYZ Classification has the value of inventory stored as the basis of differentiation. This exercise is usually undertaken once a year during the annual stock taking exercise. $\mathrm{X}$ items are those whose inventory values are high, while $\mathrm{Z}$ items are those whose inventory values are low. Understandably, $\mathrm{Y}$ items fall in between these two categories. This classification helps in identifying the items which are being extensively stocked.

\section{The VED Classification}

The VED classification is applicable largely to spare parts. Spares are classified as vital, essential and desirable. This implies that $\mathrm{V}$ class of spares have to be stocked adequately to ensure the operation of the plant because by definition the non-availability of vital spares can cause havoc and stop the wheels of organization. Some risk can be taken in respect of the E class of spares. Stocking of desirable (D) spares can even be done away with, if the lead time for their procurement is low. However, it is essential that this classification is done by the technical department or by those in charge of the maintenance of the plant. This classification can be very helpful to capital intensive process industries. A combination of XYZ and VED methods can give an idea of what are the items that should be disposed off so as to trim the inventory.

\section{The SDE Classification}

The SDE classification is one where the materials are sorted as scarce to obtain, difficult to obtain or easy to obtain. This classification is primarily directed towards controlling purchases, related supply sources.

\section{The FSN Classification}

All items are not required with the same frequency. Some are required regularly, some occasionally and some once in a while. FSN analysis places the items in three categories: Fast moving (F), slow moving (S) and non-moving $(\mathrm{N})$, Inventory policies and models for these three groups are different. 
Theoretical models have validity for (F) items with regular consumption. Spare are slow moving and require special management. Disposal policies are designed to control dead stock.

\section{The SOS Classification}

This classification is based on the seasonal availability of items as Seasonal and Off Seasonal. Seasonal items are available only for a limited period and hence they are procured to meet the demand till the next season.

\section{The GOLF Classification}

Under this classification, materials are classified according to the nature of suppliers. The nature of suppliers will determine the quality, continuity of supply, lead time, payment terms and clerical work involved, G, category covers Government supplier. O, category implies open suppliers, who usually form the bulk of suppliers. Local suppliers i.e. L category are those from whom cash purchases can be made. And, lastly F category refers to the foreign suppliers.

\section{Minimum- Maximum Technique}

The minimum- maximum technique system is often used in connection with manual inventory control system. The minimum quantity is established in the same way as any reorder point. The maximum is the minimum quantity plus the optimum lot size. Its effectiveness is determined by the method and precision with which the minimum and maximum parameters are established. If the minimum are based on an objective rational basis, the system can be very effective.

\section{The LIMIT Technique}

A technique called LIMIT (Lot Size Inventory Management Interpolation Technique) has been developed to make it possible to attain the economics of the EOQ concept and to study the alternatives available in balancing ordinary and inventory carrying costs. This technique was developed as part of a special project for the American Production and Inventory Society, Chicago in the year 1963.

LIMIT is designed to handle a family of items which passes over common manufacturing facilities. All the parts that pass through a screw machine, department or a milling machine department or all parts purchased by one buyer would be logical groups to be handled with LIMIT.

\section{Two Bin System}

The oldest and simplest is the "two bin system". One bin holds a reserve of material equal to the amount that will normally be consumed during the lead time, plus an extra amount for safety stock. The other holds the balance of the inventory. When stock in the second bin is used up, the order point is reached. A clerk requisitions a new supply of material and then draws on the reserve for his needs. When the order is delivered, the reserve supply is brought up to its former level, and the balance of the order is put into the other bin to be drawn on for immediate needs.

The two bin system is best suited for items of low value, fairly consistent usage and short lead time. It is most commonly used for office supplies. And in smaller plants it also is used for maintenance, repair and operating supplies. It rarely is suitable for production materials because it does not provide any record of stock on hand and is not sensitive to changes in demand or lead time.

The solution of the inventory problem is to find the approximate levels for holding inventories and the ordinary sequence and the quantities so that the total cost incurred is minimized. The demand and supply conditions impose the constraints within which the relevant costs have to be optimized. The three conditions can be termed as the demand being certain, risky and uncertain respectively. On the supply front, there are two possibilities which can be termed as static, if only a single supply is possible during the consumption period; and dynamic if otherwise.

\section{Kardex system}

In this system cards are vertically arranged in a metallic tray and kept in kardex cabinets specially manufactured for the purpose. Posting in these cards may be done manually but nowadays computers are taking the place of manual posting. The cards known "stock control cards" are of different types. Where the stock control card is designed to handle pricing of receipts and issues, the cards may have additional columns as per the requirement of the organisation. Normally $21 \mathrm{~cm} \times 5 \mathrm{~cm}$ or $13 \mathrm{~cm} \times 28 \mathrm{~cm}$ cards are used, colour signals are generally introduced for indicating information such as items locally purchased, imported or otherwise; orders placed, binned and taken into stock or otherwise. 


\section{Materials Requirement Planning (MRP)}

MRP has been developed in recent years and is gaining popularity in Industry, it is somewhat more elaborated and improved approach. MRP is a new solution to old problems: having stock of materials always on hand when needed without carrying excessive inventory. It is highly dependent on computer technology. It is helpful to firms with finished goods or end products which are made from a number of components. The technique separates the various components and co-ordinates purchasing and delivery with production. This results in material arriving exactly when needed for production and, at the same time, reduces the length of time when materials are held in stock.

\section{MRP operates as:-}

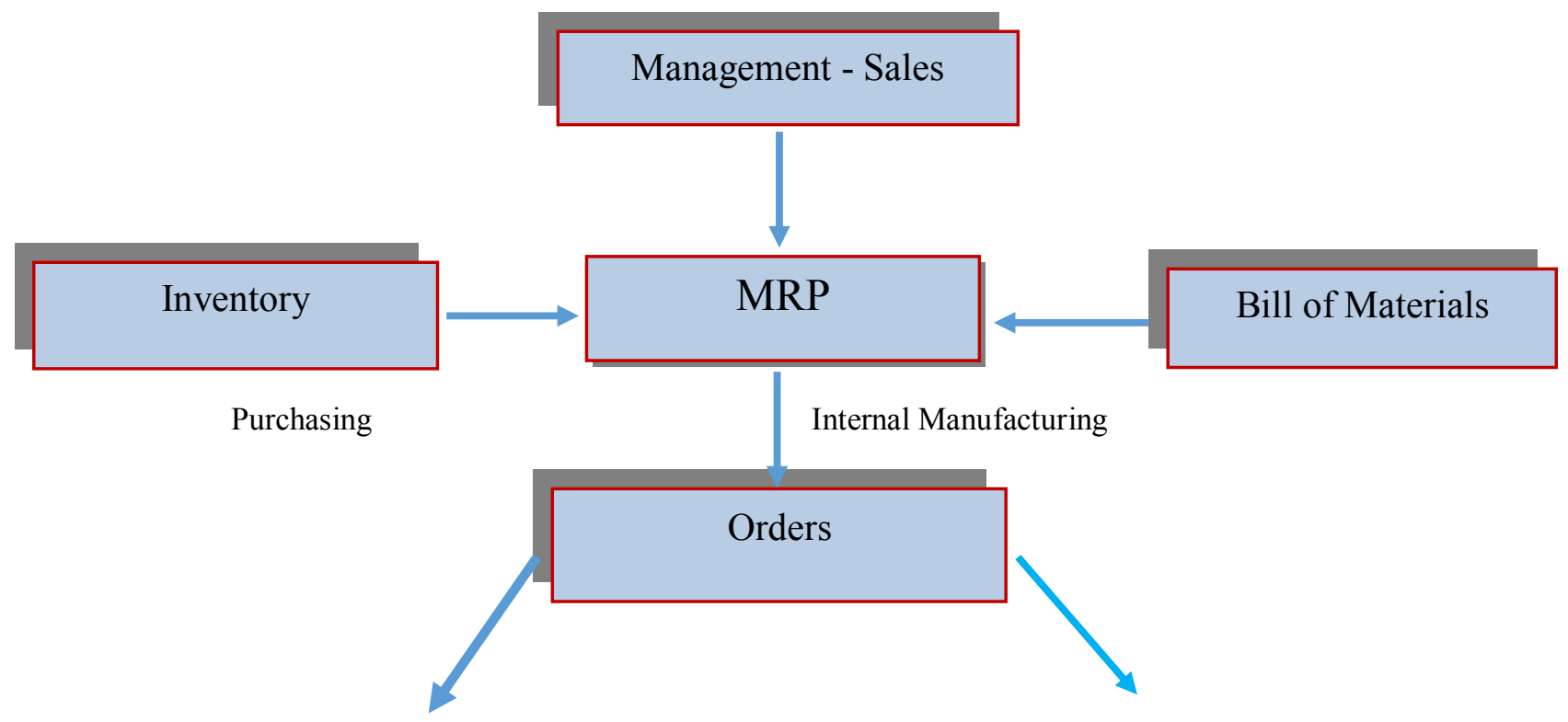

In its bare essence, MRP operates on the lines as shown above. The inputs from management and sales would be customer orders to produce within the company for stock. Basic inventory information would be provided by regular inventory records.

MRP would then co-ordinate the above information with a bill of material, usually prepared by production engineers. The bill of materials is not simply a list of parts, but, is 'structured', meaning that, it indicates the manner in which a product is put together from parts into sub-assemblies and then into final assemblies. The item listed can then be time phased and made into a master schedule, which becomes a tool of MRP. The master schedule can be thought of as a 'production forecast', which in turn can generate material and capacity records over a period of time, taking into account, the inter-dependency of these requirements. As shown above MRP, then issues orders for materials either through purchasing or through the internal manufacturing facility.

\section{Out-Sourcing}

Some years back companies usually had tendency to manufacture all the components in-house. Now-a-day's more companies are trying to adopt the practice of out sourcing. It is a practice of buying the parts and components from outside the company rather than to manufacture them internally. Many companies develop a single source of supply, and many companies' help developing small and middle size suppliers of components that they require. The concept of out- sourcing is growing faster all around the globe.

\section{JIT (Just in time)}

The concept is alternatively known as ZIPS (Zero Inventory Production System), MAN (Materials as needed), NOT (Nick Of Time), ZIN (Zero Inventories). It originated from Motomachi plant of Toyota in Japan, where the system has perfected and results achieved.

As a concept, JIT means that virtually no inventories are held at any stage of production and that the exact number of units is brought to each successive stages of production at right time. The JIT removes slack from production process such as (i) safety stock to protect against poor quality and inadequate forecasting; (ii) excessive machine 
capacity to cover long set-up time requirements; and (iii) under-utilized labour because of poor planning and scheduling. These slacks reduce productivity and increase unit costs.

JIT is about increasing flexibility and responsiveness throughout the organization. The process requires careful evaluation of all production and inventory procedures. In doing so, a company eliminates waste, improves customer service, and ultimately increases the bottom line. JIT for use in the next stage of production or for delivery to a customer has been called 'Little JIT'. The 'Big JIT encompasses the full range of organizational and operational improvements practiced by many Japanese companies and is called Japanese or lean production.

The JIT system is a new way of thinking, planning, and performing with respect to repetitive manufacturing (the industries that make discrete units in large amounts). JIT has impact on production, planning, scheduling, equipment set-up, maintenance, quality control, purchasing, receiving, inventory control, customer service and shipping. This approach combines the seemingly conflicting objectives of low cost, high quality, manufacturing flexibility and delivery dependability. Overall, just-in-time systems contribute the following benefits:

1. Reduced inventory in raw materials, parts, and finished goods

2. Better equipment utilization

3. Increased productivity

4. $\quad$ Fewer product defects

5. Greater flexibility and responsiveness throughout the organization

The western style of production planning and control for a repetitive manufacturing process is by lots. But the JIT system is based on lot less operation. The Japanese have succeeded in extending lot-less repetitive processing to levels below final assembly, leading to multi-echelon lot-less manufacturing. They have also applied lot less processing to firms making a wide variety of Consumer and Industrial Products (A. Ansari and ModarressBatoul).

The total labour productivity of a factory with JIT system is substantially higher than that of a factory without JIT (Bolwijn and Brinkman). Hundreds of successful implementations of JIT methods have been reported and they have become so common that they are no longer newsworthy. Companies such as Dover Corporation, Hewlett-Packard, $3 \mathrm{M}$, General electric, Harley-Davidson, and John Deere have reported reduction in inventories and throughput times of up to $90 \%$ and substantial improvements in productivity and on-time delivery.

JIT is not a fad: in some cases, it is a company's life blood. Don Bowker of fireplace manufacturers credits JIT for his firm's survival: “I don't think we'd be here if it wasn't JIT (Gelante, 1987). JIT philosophy and system has been successful not simply because it reduces inventories and scrap but, more importantly, because it recognizes that excessive inventories are symptomatic of more fundamental problems. The JIT system 'pulls' the material to convert into parts and assemblies, pulls the sub- assemblies for final assembly to the required level. This is achieved through Kanban.

\section{Kanban System}

Kanban is a Japanese word which means 'ticket' or 'card'. It is a kind of an order card. 'Kanban' is an information system in which the 'pull' system is affected and controlled by the use of a production order card known as kanban. These are of two types: Conveyance kanban which is carried from one process to the previous; and production kanban which is used to order production of the portion withdrawn by the subsequent process. Both types are attached to the containers holding parts.

At the start of using the content of a container the conveyance kanban is removed and taken by a worker to the stock point of the proceeding process to pick up this part. The conveyance kanban is now attached to the container holding this part. The production kanban attached to the container is removed and is sent as dispatch information for the process. This part is now produced for replenishment, as early as possible, on a first come first serve basis. Thus the production activities on the final assembly lines are connected in a manner resembling a chain to the preceding process stations and thereby JIT production of the entire production is achieved.

For the kanban system to function smoothly, several requirements must be met. The production steps must be like a tree where sub-assembly and fabrication stages (roots) flow smoothly into the final assembly (trunk). A subassembly serving more than one node may create problems and imbalances. It must be possible to manufacture the order quantity of each state/station in the same amount of time. This keeps the stations in balance. The time required 
to changeover from producing one part to another must be kept at an absolute minimum to enable each station to adapt to new orders readily (Srinivasan, 1990).

The equation for calculating the number of kanbans is as follows:

Where,

$$
\mathrm{Y}=\frac{\mathrm{D}(\mathrm{Tw}+\mathrm{Tp})(1+\alpha)}{a}
$$

$\begin{array}{ll}\mathrm{Y} & =\text { number of kanbans } \\ \mathrm{D} & =\text { demand per unit time } \\ \mathrm{T}_{\mathrm{w}} & =\text { waiting time for the kanban } \\ \mathrm{T}_{\mathrm{p}} & =\text { process time } \\ \mathrm{a} & =\text { container capacity } \\ \alpha & =\text { is a policy variable } \\ \text { there will be } 0 \text { for } \alpha, 1 \text { for a, and } 0 \text { for } \mathrm{T}_{\mathrm{w} .}\end{array}$

1. Economic Order Quantity (EOQ) Concept

Economic order quality is referred to that size of order which gives maximum economy in purchasing the materials. It is also known as Optimum or Standard Order Quality. EOQ offers solutions to inventory problems. The concept of EOQ is equally more applicable to raw materials, storage of finished goods and in transit inventories. Economic order quantity concept helps in finding approximate levels for holding inventories. It facilitates the fixation of ordering sequence and the quantities so as to minimize the total material cost. Thus, before taking a decision on economic order quantity, the inventory costs are considered and analyzed threadbare. EOQ is the point of minimum cost at which the ordering cost will be just equal to the carrying cost such that neither excess material is ordered, nor too many orders are placed for the same material during a period in time. This also depends upon the nature and complexity of production etc. One of the formulae for calculating EOQ is as:

Where:

$$
\mathrm{EOQ}=\sqrt{\frac{2 \mathrm{DS}}{\mathrm{CI}}}
$$
$\mathrm{Q}=\quad$ Ideal purchase quantity
$\mathrm{S}=\quad$ Cost of ordering
$\mathrm{D}=\quad$ Annual usage or demand in units
$\mathrm{I}=\quad$ Inventory carrying cost expressed as a percentage of annual inventory
$\mathrm{C}=\quad$ Unit cost of material

$$
\mathrm{EOQ}=\sqrt{\begin{array}{l}
\frac{\mathrm{OR}}{2 \times(\text { Annual usage } \text { or demand in units }) \mathrm{x}} \\
\begin{array}{l}
\text { (order cost in re } \text { - order }) \\
\text { (carrying cost of material in Re. unit }) \mathrm{x}
\end{array}
\end{array}}
$$

Here, $($ Inventory carrying cost $)=($ Average Inventory $) \times($ Unit cost of material) $\mathrm{x}$ (Inventory carrying cost in percent And where: Annual Set - up cost $=\frac{\mathrm{DS}}{\mathrm{Q}}$ per period)

Economic order quantity is technique which solves the problem of the materials manager. EOQ or Opt Q (optimum quantity)is the order size at which the total cost, comprising ordering cost plus carrying cost is least, which is illustrated graphically as:- 


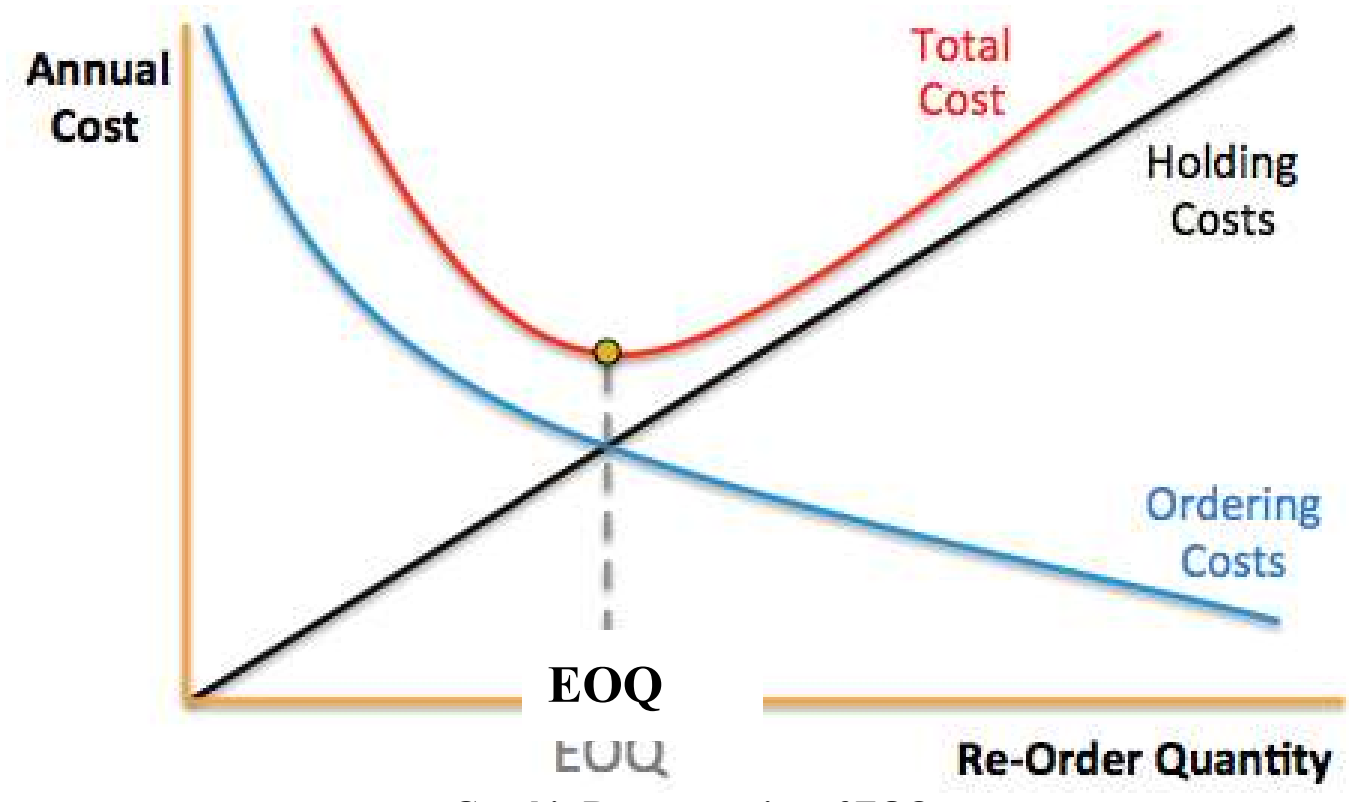

Graphic Representation of EOQ

\section{Order Quantity Size (Q)}

\section{Inventory Review Policies}

Inventory policy is about deciding whether the inventory position will be reviewed on a continuous or periodic basis.

\section{Periodic Review Policy}

Traditionally most organizations use 'periodic review policies'. The organisation reviews the inventory for the product and places orders at fixed time intervals. The amount ordered each time varies according to the inventory position and the expected demand. This review policy may be very risky for the organisation as inventory may go very low until the next review without company's knowledge. As shown in figure below periodic review policy has typically variable order quantities but fixed time intervals between orders.

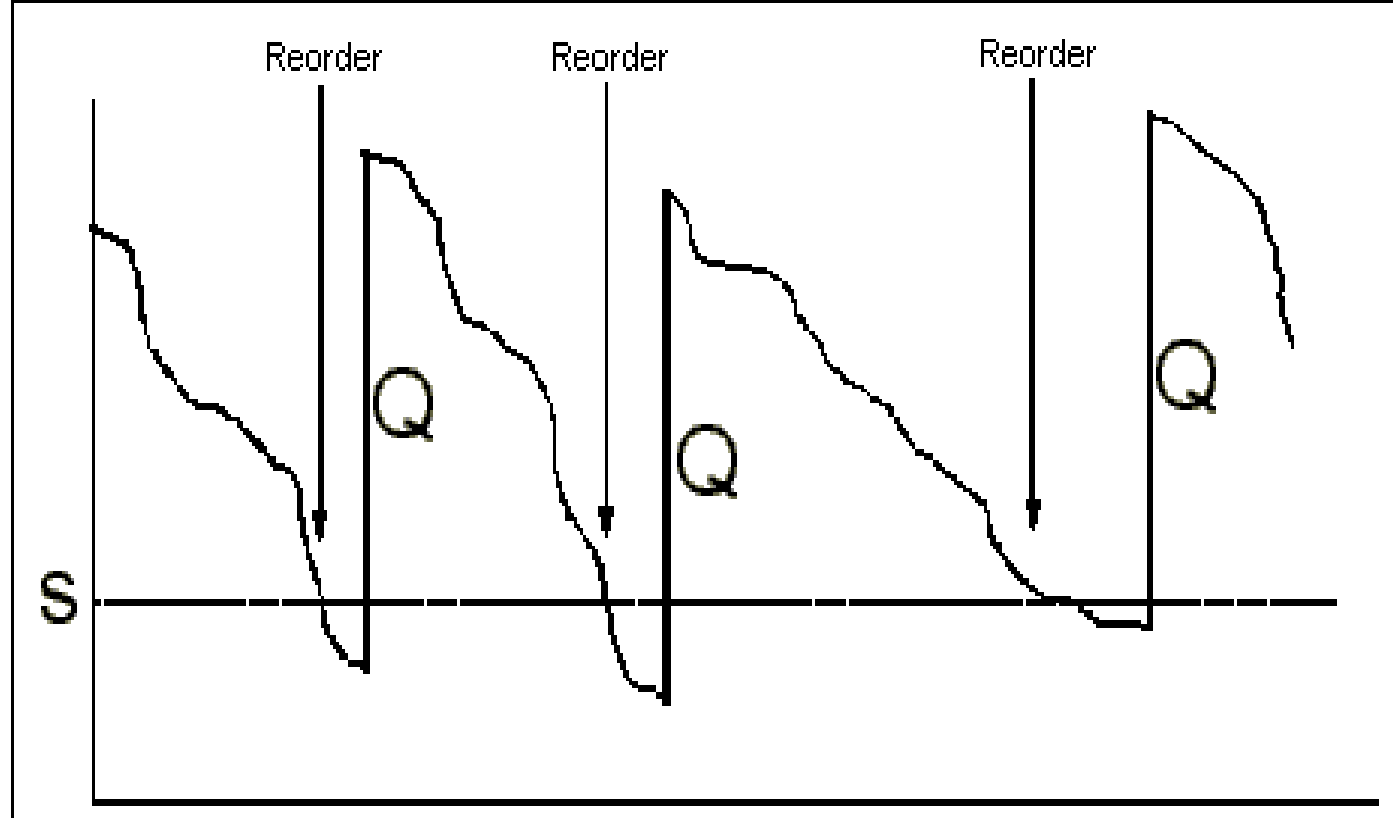

Inventory pattern for a Periodic Review Policy 


\section{Continuous or Perpetual Review Policy}

The advanced computer technology helps in maintaining inventory levels which is real time information on the inventory position of even the thousands of products. It has become wide spread as it is less risky; it also requires lesser inventory levels. The company is always aware of its current inventory position; as soon as inventories drop to a predetermined level called 're-order point' the company can place an order of some fixed amount. As the figure below shows that this system of continuous or perpetual review system have fixed order quantities but variable time intervals.

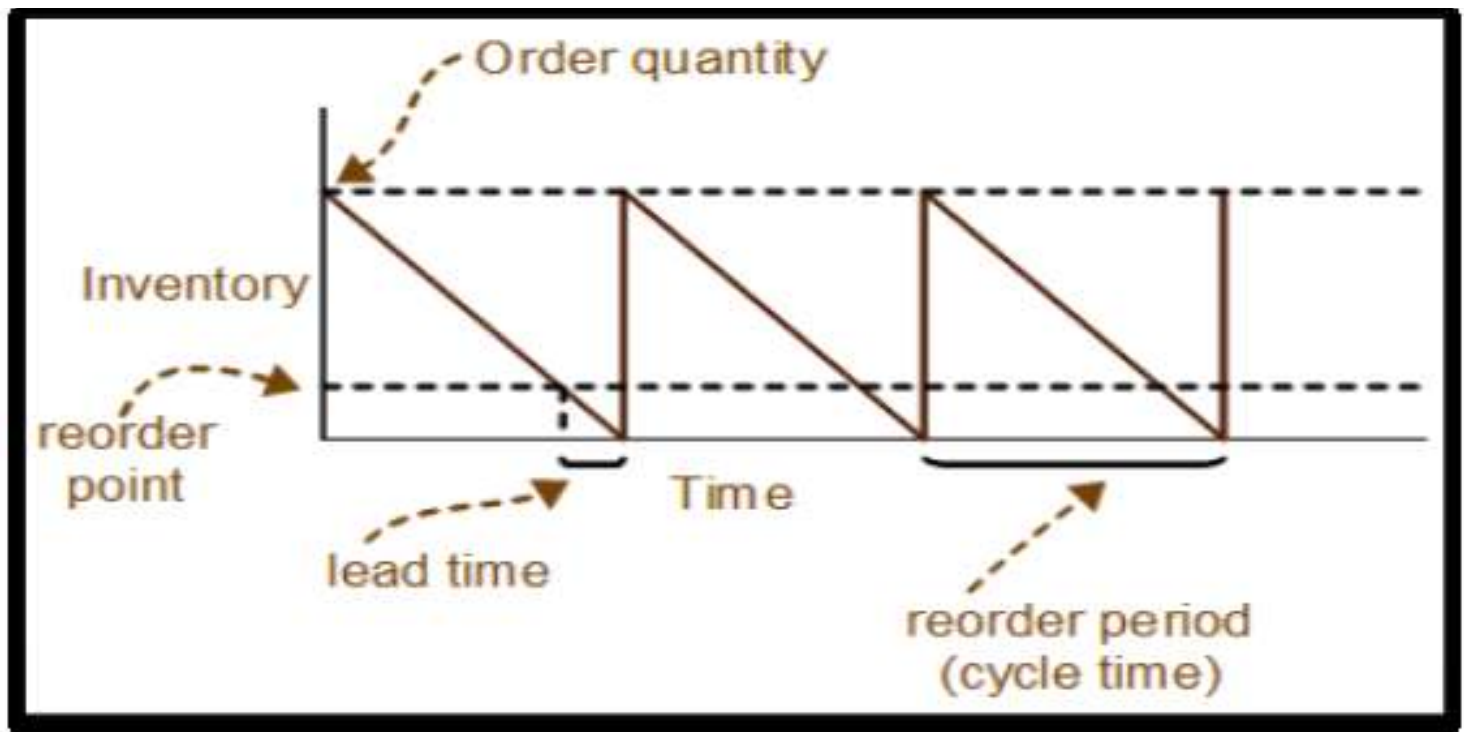

Continuous or perpetual review policy

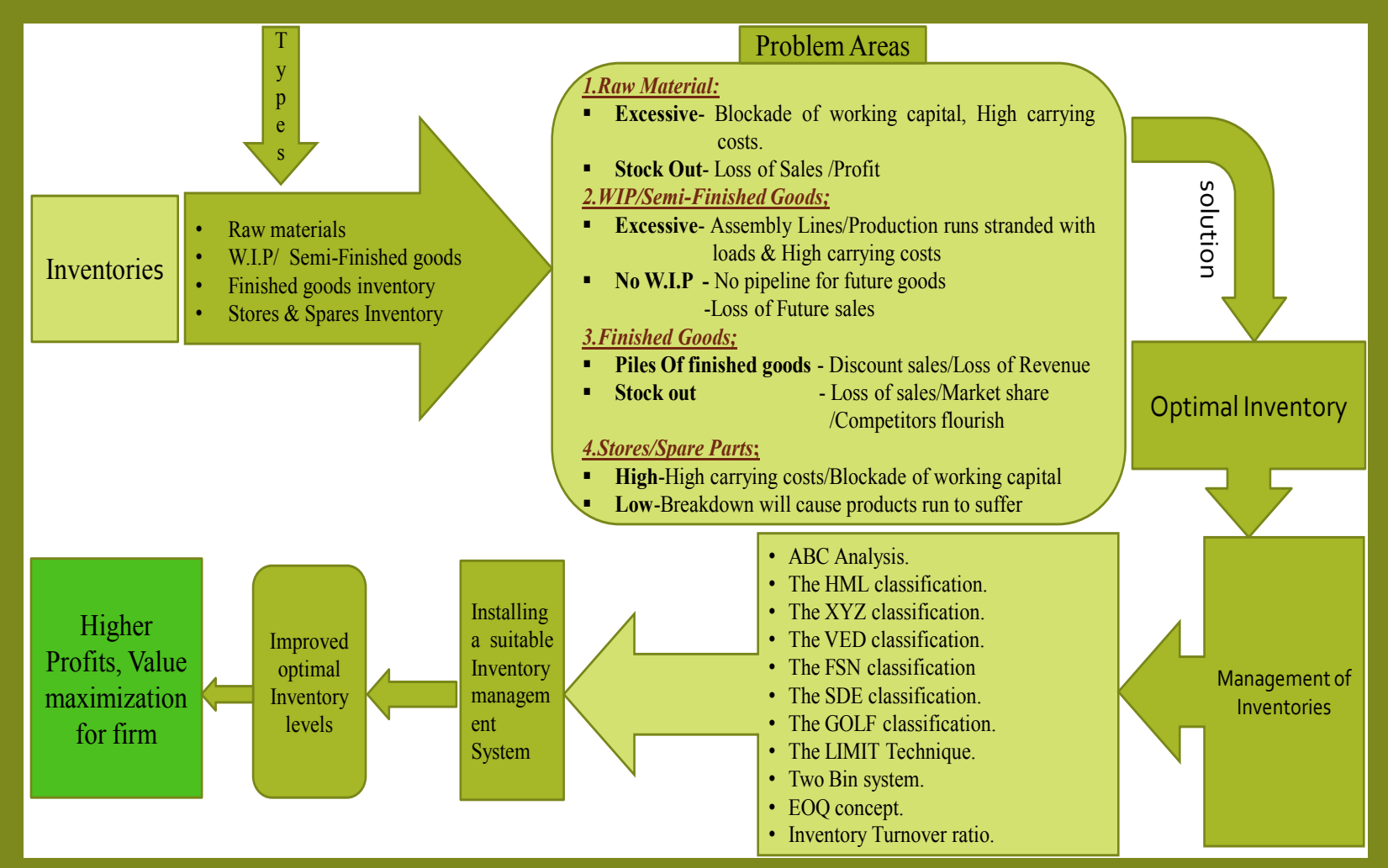

Frame Work 


\section{The General Framework for Inventory}

Inventory management problems in any manufacturing or non-manufacturing organizations can be a cause of hazardous situation. To evade such problems an intrinsic study of inventory theory becomes quite necessary. The general framework for inventory models has the following five components:

\section{Demand}

Inventory decisions are always made with reference to the future demand. It is an indispensable component of inventory management. The decisions regarding the level of Inventory and re-ordering are taken when the manager is certain about the requirements in his department

\section{Order Quantity}

Most material requirements are continuing requirements, cumulative or total needs. This system of requirements is a better guide than the day to day needs. In the procurement function there is a requirement for a most economical ordering quantity. In order to establish an economic order quantity two extreme views are encountered. They are:

i) The production oriented solution i.e. to procure in very large lots in order to minimize the set-up and procurement costs

ii) The treasurer, comptroller or accountant oriented solution which believes in production in very small lots to minimize the investment in stock.

The above two are extreme cases, none of them holds positively a better foothold, and rather the answer is found in between the two i.e. a combination of both. The economic order quantity should be established in such a way so as to balance all the variable costs of inventory. The variable costs of inventory are those which vary with the size of the order quantity. The objective of economic order quantity calculations is to determine an order quantity so that the total variable cost of inventory is kept to the minimum.

\section{Lead Time}

The interval between the time that the need for material is determined and order placed and the time this material is actually manufactured and delivered is known as lead time. The longer the lead time, the more time is required to get the results of production. The lesser the lead time more swift will be the results of production. If lead time is zero, no safety stocks would be required, as replenishment of the stock can be done immediately without any problem. In case the lead time is longer, it is more difficult to predict the usage or consumption, while the order is open.

\section{Safety Stock}

The demand or usage is not generally known with certainty in practice. Usually it fluctuates during a given period of time. The demand for finished goods inventory is subject to the greatest fluctuations while as the usage of raw materials inventory and in transit inventory are both dependent on the production scheduling and is much more predictable. In addition to demand or urge, the lead time required to receive delivery of inventory, once an order is placed is subject to some variation. Owing to these fluctuations, it is not feasible to allow expected inventory to fall to zero before a new order is anticipated, as the firm could easily do when usage and lead time were known with certainty.

Most firms maintain some margin of safety or safety stock to satisfy the demand. In this connection, the order point is a predetermined signal which will indicate to the stock controller that he should consider the possibility of reordering the stock item in question. It is expressed in units of material as it is stocked and ordered. Whenever, an issue from stock causes the coverage of an item to drop below this pre determined point, the item should be investigated. The order point must be selected at a figure high enough so that the state will be sufficient to satisfy the maximum number of expected demands upon the stock during the period when the replacement stock is on order.

Order point $=$ Maximum expected usage during lead time.

Lead time cannot always be accurately determined and the usage during lead time cannot always be accurately forecasted. However, in cases where both of these are absolutely predictable, the order point is stated:

Order point $=$ Known requirements during lead time.

When material usage rates are based on estimates rather than firm figures, it is expedient to make an upward adjustment of the order point. This process is done through the introduction of safety stock.

Order point $=$ Expected lead time usage + safety stock 
Thus safety stock is referred as an extra inventory needed to protect against unrealizable and inaccurate forecasts. Excessive safety stocks boost inventory investment; inadequate safety stocks fail to have the desired protection against stock outs. Thus when forecasts of lead time and usage are perfectly accurate then:

Maximum inventory $=$ order quantity + safety stock

Minimum inventory $=$ safety stock

Average inventory $=1 / 2$ of the order quantity + Safety stock (if usage is steady)

\section{Cost of Possession of Inventories}

The carrying of inventories involves exorbitant cost. The Annual Carrying Cost of carrying a production inventory averages approximately $25 \%$ of the value of Inventory (Bangs, 1955). The annual carrying cost of inventory averages somewhat over $20 \%$ of the total inventory Value, exhibiting a range of somewhat $10-34 \%$ (Welch, 1956).

There are numerous costs involved in possessing of inventories: They are as follows

\section{Inventory Capital Cost:}

When a firm purchases production material and carry inventories, it leaves a lower capital available to the firm in the form of working capital for other purposes. To ascertain, whether the capital employed in inventories has been justified or not, the ratio of sales to inventory should be calculated. To raise this ratio, the company should either reduce inventories or increase sales without a corresponding increase in inventories. In this way the company's earnings on investment will boost up. Since money tied up in inventories represent a 'blockage of capital, therefore, it is logical for the company to charge a rate of interest equal to that it could have earned if invested somewhere else. The opportunity cost varies from company to company and from year to year. At the peak of the business cycle, carrying costs can be extremely high because very profitable alternative opportunities are available and vice-versa.

a) Inventory risk Cost: It includes insurance, obsolescence, shrinkage, damage, deterioration and relocation costs. The Company may be required to pay insurance charge to insure their assets against possible loss from fire and other forms of damage. This insurance cost is a 100 percent variable cost. It is a fact that whenever there are inventories, a certain percentage of a given inventory becomes absolute. No matter how diligently the warehouse manager guards against this occurrence, there is always a certain amount of obsolescence and deterioration. Well managed companies ruthlessly weed out surplus inventory and dispose it off from the warehouse. "The general rule is never to hold inventories for which there is no immediate need. And with new products being introduced at an increasing rate, the probability of occurrence of obsolescence is increasing accordingly. Consequently, the larger the inventory, the greater is the absolute loss from this source."(Naddor, 1966)

b) Property Taxes: This cost may vary from state to state and is $100 \%$ variable in nature. Property taxes are levied on the assessed value of a firm's property. The greater the inventory value, the greater the property value and consequently the higher is the firms tax bill.

c) Inventory storage space costs: The most obvious cost is the storage cost, which includes rent for storage facilities. Salaries and personnel and related storage expenses are involved in it storage cost, however vary with the type of material stored, type of storage facilities used and so on. It is high for hazardous, perishable and sensitive inventories.

d) Acquisition cost: Most companies carry inventory not because they need protection against stock-outs, but because of reducing their cost of acquisition. Since by ordering and buying large quantities they reduce both purchase cost and order cost. Therefore, it becomes necessary to know the cost of writing a purchase order, the cost of stocking material and the quantity discount available for the item being purchased/

e) Purchase cost: When a company buys in large quantities suppliers will cut their prices because their costs are lower when they get a simple large order instead of a number of small orders. This enables them not only to reduce their administrative expenses but by manufacturing in larger lots they even reduce unit cost of production. A larger purchase order also increases buyer's bargaining power and it is easier to wrangle concerns from suppliers.

f) Ordering cost or Setup cost: Besides, these larger orders also reduce most other costs of acquisition e.g. the cost of making the purchase, excluding receiving, and paying for the material, interplant and intra plant transportation, packing and so on. However, ordering cost is insignificant only with purchases of very high value. Order costs may be substantially high if the purchase lots are in small items.

g) Shortage or Stock out cost: Sometimes a customer wishes to buy a product and it is not available, the supplier incurs a cost of not only losing profit but also future profits in case customer changes the supplier. These costs are called stock out or shortage costs e.g. back ordering and lost sales. 


\section{Types of Inventory Cycles}

The three basic inventory control systems are as under:

The Fixed-Order Quantity System:

Fixed order quantity systems are common where a perpetual inventory record is kept and where only low valued items are stocked. The inventory is under rather continuous surveillance so that notice can be given when the recorder level is reached.

\section{Fixed Reorder Cycle System}

This system focuses control in inventory on a periodic basis, so that orders are placed weekly, monthly, or by some other cycle. However, the size of the order varies for each cycle to absorb the fluctuations in usage from time to time. Fixed recorder cycle systems are prominent sight higher valued items and where a large number of items are regularly ordered from the same purchaser. With the fixed cycle ordering, freight cost advantages are often be gained by grouping these orders together for dispatching.

\section{Base Stock System}

The base stock system is a blend of the fixed quantity and fixed cycle systems. Under this system, stock levels are reviewed on a periodic basis, but orders are placed only when inventories have fallen to a pre-determined reorder level. At this point, an order is placed to replenish inventories to the base stock level, which is sufficient for buffer stock plus a fixed quantity calculated to cover current usage needs. The base stock system has the advantage of close control associated with the fixed cycle system which makes it possible to carry minimum buffer stocks. On the other hand, since replenishment orders are placed only when the reorder point has been reached, fewer orders, on the average, are placed so that order costs are comparable to those associated with the fixed quantity systems.

\section{Valuation of Inventories}

The methods usually taken for valuing the materials inventory are:

1. FIFO(First in First out) as its names implies, FIFO assumes that the material purchased are issued in strict chronological order i.e. whatever is received first, is consumed first (First in First out)

2. LIFO (Last in First out) this method assumed that materials coming in last are issued first. In this method also, there will be no intrinsic profit or loss in material issues.

3. Average Cost Method in average cost method; the issues to the production department are divided into equal batches from each shipment at stock.

4. Standard Cost Method in standard cost method; a standard rate for the material is fixed based on the detailed analysis of market prices.

5. Market Price Method in market price method, the prevailing market rate of the material is applied for costing the material at the time of issue.

\section{Inventory Turnover Ratio}

Inventory Turnover Ratio is also known as Inventory Turns. The manufacturing units are more interested in inventory turnover ratio or average days to sell inventory as it tells them about relative inventory levels. It is a ratio showing how many times a company's inventory is sold and replaced over a period. The days in the period can then be divided by the inventory turnover formula to calculate the days it takes to sell the inventory on hand or 'inventory turnover days'.

Generally calculated as:

$$
\text { InventoryTurover }=\frac{\text { Costofgoodssold }}{\text { (opening inventory }+ \text { closing inventory) } / 2}
$$

$=$ Cost of Goods Sold /Average Inventory.

The Average Days to Sell Inventory $=$ Number of Days a Year / Inventory Turnover Ratio $=365$ days a year / Inventory Turnover Ratio.

The ITR estimates number of times the inventory turns over a year. E.g. if an organisation has two inventory turns it has a six months stock on hand, which is generally not a good figure. Whereas a factory that has six turns to twelve turns has improved effectiveness.

\section{Computers in Inventory Management}

The computerized system of controlling Inventories is being adopted by many companies, irrespective of their size. Small or large companies easily track their Inventories with the help of computerized Inventory Control System. The 
Inventories are counted automatically, recording of withdrawals and revising the balance is updated automatically. The in-built system of placing an order notices that the reorder point has been reached; it is inevitable for larger stores were thousands of items are being carried. There is also a link between the buyers and suppliers, when the buyers re-order point is reached, the suppliers computer receives the information and thus activates the supply process.

With advancement of technology and because of increasing industrial and commercial complexities organizations are taking the help of computers for solving their inventory problems. There are different inventory management softwares that help us to keep a track of inventories. Their use yields us following benefits:

1. They eliminate the use of manual inventory management processes and thus reduce errors and lead time.

2. They provide managers an easy access to numbers that are needed for reporting and re-stocking the information.

3. They provide complete real-time visibility of demand, costs, supply and fulfillment measures and trends.

4. They significantly improve the relationships with vendors, suppliers, and partners by providing them with selfservice and real-time visibility.

5. They improve the demand planning and reduce the forecast error rate.

6. They help in Reducing the lost sales and backorders.

7. They help in increasing the inventory turnover.

8. They help in managing the large numbers of styles efficiently and accurately.

9. They improve the management understanding of forecasting and inventory management process and performance.

10. They help in increase sales and profits.

\section{Inventory Control Tracker (ICT)}

Inventory control tracks the inventory records and updates automatically. The notifications of reaching expiration date are received by inventory control tracker. It tracks multiple warehouses and items, by item number, lot number, production code, date, carrier, and consignee.

\section{Inventory Management Software}

There are many software available for better inventory management performance, e.g. Advance ware Technologies, advancePro Inventory, NetSuite, Direct Tech Inc. Forecast 21 Inventory forecasting, which can be used to manage the inventories. Moreover there are various other inventory Optimization Softwares, some of which are mentioned below:

1. Mincom Critical Inventory Optimization (MCIO): It is an intelligent, predictive software solution that identifies the optimal holdings of every stock item based on usage patterns and criticality. MCIO automatically analyzes and adjusts stock levels and reordering requirements on an ongoing basis.

2. SmartOps Enterprise Inventory Optimization (EIO): It is a comprehensive suite of software modules that enables organizations to plan and manage inventories across global supply chains. SmartOps EIO encapsulates sophisticated, proprietary algorithms into software that integrates with enterprise planning systems and handles large-scale, complex supply chains in a dynamic and automated manner.

3. JDA's Network \& Inventory Optimization: It uses deterministic and stochastic optimization combined with flexible user-interface and analytical workbenches.

4. Smartcorp: It uses proven forecasting solutions that accurately predict, for each product item, the most likely or expected value for demand over a given lead time. The safety stock recommendations and stocking level estimates that are generated are immediately available for use in other parts of your corporate planning system.

\section{Statement of the Problem:}

It is due to the increased global complexity that the companies are experiencing long lead times and a high demand volatility. The result is in an increased emphasis on managing inventory. The Identification of the best practices and the best tools to accomplish it has become critical. Inventories have come to be recognized as a vital problem area needing top priority in such a rapidly growing sector. Apart from fire fighting and adhoc measures, hardly any organized approach seems to be in vogue in most of our enterprises. For concrete results on sustained basis, the basic cause at the root of the problem needs to be identified and dealt with efficiency. Inventory control thus deserves highest attention. Inventory control is a technique that helps in maintaining stock at an optimum level. The reason of carrying inventories is to ensure regular supply of materials as and when required. Insufficient inventories might hamper production process and mitigate the sales volume, while as too much inventories tie up working 
capital and increase carrying costs. Therefore the necessity is to strike balance between stock out and excessive stock.

The process of inventory management has gained importance all over the world, in India with the increase in the size of business enterprise, complex production technology and the adoption of professional management techniques inventory management has become a necessity. The present study is aimed to explore the researches on inventory related issues keeping in view the following objectives:

\section{Objectives:-}

1. The first aim of the study is to make an in-depth literature review in the area of inventory management systems prevalent on ground and in theories, and to provide an overview of the subject matter.

2. Thesecond aim is to examine the Inventory management system and to provide an overview of the subject matter.

\section{Conclusion:-}

It has been found that there is a broad gap between the theoretical world of knowledge and practice. It has also been seen that the arena of knowledge is widening but the practical implication is lagging behind in such a significant sector. If we talk of Indian context the talked about gap is too wide. This is true about almost all the sectors of the economies worldwide. While going through the available literature it was found that almost each country that has a growing industrial sector is trying to tackle with the problem of deciding the efficient Inventory systems. Although during browsing the work of researchers in the field of Inventory management, it was deduced that the Inventory management continues to be a problem area for almost all the manufacturing organizations. As a matter of the fact much attention is devoted towards creating an efficient inventory management system based on the rationale "not out of stock and not excessive stock' (optimum level). Thus Management of inventories occupies a central place among many management problems and hence has to be addressed seriously to ensure healthy textile sector in world particularly in developing countries. A lot of work is yet to be done to improvise this sector. And therefore leaves a long path to be followed by researchers.

\section{References:-}

1. Ansari, A. BatoulModarress, 1985, Just in time purchasing: Problems and solutions, Journal of purchasing and material management, pg 11 .

2. Axsater, S, 2001, A framework for decentralized multi-echelon inventory control. IIE Transactions, 33, pg 9197.

3. Bolwijn, P.T, S,Brinkman, 1987, Japanese manufacturing: strategy and practice, Long range planning, Pg 25.

4. Chandra, Prasana, Financial Management theory and Pracice, Tata McGraw-Hill Publishing Company limited, New Delhi, ISBN 0-07-462063-0,Pg. 366-379.

5. Chunawalla, S.A., Patel, D.R., Production and Operation management, Himalaya Publishing House, ISBN: 978 93-5024-092-2, Pg 513.

6. Gelante, P.Steven.1987, Small manufacturers shifting to Just-in-time techniques, Wall Street Journal.21 ${ }^{\text {st }}$ Dec.

7. Harrington, L., 1996. Untapped savings abound. Industry Week, 15th July, pg 53-58.

8. L.P. Alford Bangs. J.R, 1955, Production Handbook, The Ronald New York, pg, 396-397.

9. Naddor, E, 1966, Inventory Systems, John Wily and Sons, New York, pg, 194.

10. Numairaet. al., 2019, "A Cross Country Research Review With Special Reference to Management of Inventories in Textile Industry. 'International Journal of Scientific Development and Research. Vol. 5, Issue-5, pg. 44-50, doi.one/10.1729/Journal.23548

11. Pandey I.M, Financial Management, Vikas Publishing House Pvt. Ltd., 576, Masjid road, Jangpura, New delhi110014, ISBN 81-259-1658-X. Pg 661-663.

12. Rao, R.S., Problems in Inventory management, LokUdyog, January, 1977, Vol, XXL, No.34, p.21-22.

13. Shafi, Mohammad, 1992, Management of Inventory-An Analysis Of Its Vital Dimensions, Management Review, NarseeMonjee Institute of Management Studies (NMIMS), Mumbai, pg 28-38.

14. Shafi, Mohammad, 1994, Unused Inventories -An Analytical Study, Management Review, NarseeMonjee Institute of Management Studies (NMIMS), Mumbai, pg 27-29.

15. Sharma, P.C, 1984, Materials Management, Kitab Mahal, Allahabad.

16. Shore, Barry, 1980, Operations Management, Tata Mcgrah-Hill, New Delhi.Pg.363. 
17. Srinivasan,A.V,1990, Japanese Management-the Indian context, Tata McGraw-Hill Publishing company Ltd, ISBN, 0-07-460352-3, 4/12 Asaf Ali Road, New Delhi,110002.Pg. 99-102.

18. Welch, W. Everett, 1956, Tested Scientific Inventory Control, Management publishing corp. Greenwich.conn.,pg, 64.

\subsection{URL}

1. www.wikipedia.com.

2. $\quad$ http://www.advanceware.net

3. http://www.netsuite.com/portal/products/netsuite/supply-inventory/main.shtml

4. http://www.direct-tech.com

5. $\quad$ https://en.wikipedia.org/wiki/APICS

\section{Websites:}

1. www.business-standard.com

2. www.fibre2fashion.com

3. www.statista.com 